\title{
Role of IoT Technology in Agriculture for Reshaping the Future of Farming in India: A Review
}

\author{
Pradeep Kumar Singh ${ }^{\text {1* }}$, R. K. Naresh ${ }^{1}$, Akash Kumar ${ }^{2}$, Lalit Kumar ${ }^{3}$, \\ M. Sharath Chandra ${ }^{1}$, Shivangi ${ }^{1}$ and Prasant Ahlawat ${ }^{4}$ \\ ${ }^{1}$ Department of Agronomy, Sardar Vallabhbhai Patel University of Agriculture \& Technology, \\ Meerut, U.P., India \\ ${ }^{2}$ Department of Floriculture \& Landscape Architecture, Dr. YSP University of Horticulture \& \\ Forestry, Solan, H. P., India \\ ${ }^{3}$ Indian Institute of Farming System Research, Modipuram, Meerut, U.P., India \\ ${ }^{4}$ Department of Plant Pathology, C.C.S University Campus, Meerut, U.P., India \\ *Corresponding author
}

\section{A B S T R A C T}

\section{Keywords}

IoT, Smart

Farming, IoT

sensors, IoT in

agriculture, Smart

devices

Article Info

Accepted:

07 January 2021

Available Online:

10 February 2021
The Internet of Things (IoT) is an emerging paradigm in which physical objects are connected to each other and user via the Internet in order to share information between devices and systems. Farming is an occupation which is playing the ultimate role for survive of this world. It supplies maximum needs for the human being to live in this world. Also, with the revolution of technology and demand increase for the food with an increase in the number of population by 2030. Technology has played a major role in the recent revolution in agriculture, which faces major challenges, including meeting the needs of a growing world population, reducing production costs and adapting to climate change as using IoT and moving into the smart farming as the promises way. The use of IoT has become more rapid in terms of services and users. Besides, IoT requirements for automation, interoperability, and installation are very easy. Moreover, a lot of researchers take attention to the importance of the use of IoT in their studies even with appearing some challenges such as collecting data and security. At the same time the implementation applications of IoT to reality it came with the successful result through improved crop yield using data statistics and managing of meteorological farm stations. In the field of Farming, the improvement with the implementation of Automation is also taking place with the invention of Internet of Things. In this paper, several benefits and challenges of IoT have been identified. We present the IoT ecosystem and how the combination of IoT and DA is enabling reshaping the Future of Farming in India.

\section{Introduction}

India is a diverse and global agricultural powerhouse with its agrarian culture and varied regional climate significantly contributing to the global food basket. According to FAO (2013) world population is estimated to increase by $33 \%$ in the year 2050 and rural Agricultural production will have to increase by $60 \%$ to feed this population. 
Farming must along these lines change itself on the off chance that it is to bolster a developing worldwide populace and give the premise to financial development and neediness lessening. Environmental change will make this assignment more troublesome under the same old thing situation, because of unfavorable impacts on horticulture, requiring spiraling adjustment and related expenses. IoT innovations for small agricultural operations can significantly increase profit margins by minimizing the need for manual labour with automation, expediting machinery commands with remote and real-time monitoring, and allowing farmers to utilize resources more efficiently with preventative maintenance and environmental prediction. Mass embracement of these technology advancements in agriculture will allow small land holding farmers to manage more acreage, provide higher potential for profit, and higher yields on the upfront investments.

IoT has the potential to transform agriculture in several aspects. On the other hand, IoT and big data enable to improve productivity. IoT brings loads of data collected by smart sensors that could track several factors such as weather conditions, crop's growth progress, soil quality, or even health of livestock.

Unfortunately, only a limited portion of the earth's surface is suitable for agriculture uses due to various limitations, like temperature, climate, topography, and soil quality, and even most of the suitable areas are not homogenous. When zooming the versatilities of landscapes and plant types, many new differences start to emerge that can be difficult to quantify. Moreover, the available agricultural land is further shaped by political and economic factors, like land and climate patterns and population density, while rapid urbanization is constantly posing threats to the availability of arable land. Over the past decades, the total agriculture land utilized for food production has experienced a decline (FAO, 2019). In 1991, the total arable area for food production was 19.5 million square miles $(39.47 \%$ of the world's land area), which was reduced to approximately 18.6 million square miles $(37.73 \%$ of the world's land area) in 2013 (Zhang et al., 2018). Further examination showed that every crop field has different characteristics that can be measured separately in terms of both quality and quantity. Critical characteristics, like soil type, nutrient presence, flow of irrigation, pest resistance, etc., define its suitability and capability for a specific crop. In most of situations, the differentiations of characteristics can exist within a single crop field, even if the same crop is being cultivated in entire farm; hence, site-specific analyses are required for optimal yield production. Further, adding the dimension of time, specific crops in the same field rotate seasonto-season and biologically reach different stages of their cycle within a year in areas where location and temporal differences result in specific growth requirements to optimize the crop production. To respond to these demands with a range of issues, farmers need new technology-based methods to produce more from less land and with fewer hands.

For this, the need of smart agriculture arises, as $70 \%$ of farming time is spent monitoring and understanding the crop states instead of doing actual field work (Navulur et al., 2017). Considering the vastness of the agriculture industry, it incredibly demands for technological and precise solutions with the aim of sustainability while leaving minimum environmental impact. Recent sensing and communication technologies provide a true remote-eye in the field\| ability in which farmers can observe happenings in the field without being in the field. Wireless sensors are facilitating the monitoring of crops constantly with higher accuracy and are able 
to, most importantly, detect early stages of unwanted state. This is the reason why modern agriculture involves the usage of smart tools and kits, from sowing to crop harvesting and even during storage and transportation. Variety of autonomous tractors, harvesters, robotic weeders, drones, and satellites currently complement agriculture equipment. Sensors can be installed and start collecting data in a short time, which is then available online for further analyses nearly immediately. Sensor technology offers crop and site-specific agriculture, as it supports precise data collection of every site.

This review study aims to identify how IoT is used with reshaping the Future of Farming in India smart farming by (i) presenting a systematic review of the state of the art of the IoT adoption in smart agriculture and (ii) identifying the most commonly used network protocols and technologies and their applicability to the proposed solutions. To give a more up-to-date view to the reader about the smart agriculture research field, this review article surveys literature until year 2020 and evaluates the acceptance of (new) IT technologies, such as big data, computer vision and artificial intelligence in the smart agriculture field. This review complements the analysis already carried out by the academy by performing a comprehensive review of the state-of-the-art of IoT in smart farming. To do so, we rely on IoT architecture to identify the technologies that enable IoT in smart farming. Moreover, this review contributes to the existent literature by reporting a change in the treatment of data in recent works: while previous work showed that the majority of decision support systems used simple processing mechanisms to handle data collected in real-time, more recent work showed an increasing number of management systems that use complementary technologies that rely on processing large amounts of data.
The uses and application domain of IoT based smart farming is not confined to the large cultivation activities but also extends to inspire other developing basic patterns in horticultural as in organic farming, small space cultivation like kitchen gardening, preservation of quality crops and also helps in upgrading the straightforward cultivation processes. IoT based smart cultivation process can give incredible advantages to deal with natural issues, including more productive water utilization, or streamlining of information sources and optimized treatments. Presently, the talk of town is all about the significant contribution and utilizations of IoT based smart farming that are revolutionizing the conventional way of monitoring farms and increasing income in agri-businesses.

Recently, the Internet-of-Things (IoT) is beginning to impact a wide array of sectors and industries, ranging from manufacturing, health, communications, and energy to the agriculture industry, in order to reduce inefficiencies and improve the performance across all markets (Hi et al., 2019; Elijah et al., 2018). If looking closely, one feels that the current applications are only scratching the surface and that the real impact of IoT and its uses are not yet witnessed. Still, considering this progress, especially in the near past, we can predict that IoT technologies are going to play a key role in various applications of the agriculture sector. This is because of the capabilities offered by IoT, including the basic communication infrastructure (used to connect the smart objects-from sensors, vehicles, to user mobile devices - using the Internet) and range of services, such as local or remote data acquisition, cloud-based intelligent and agriculture operation automation. Such capabilities can revolutionize the agriculture industry which probably one of most inefficient sectors of our economic value chain today. Figure 1a provides the main 
drivers of technology, while figure $1 \mathrm{~b}$ highlights the major hurdles of technology implementation in smart agriculture.

Researchers and engineers around the globe are proposing different methods and architectures and based on that suggesting a variety of equipment to monitor and fetch the information regarding crop status during different stages, considering numerous crop and field types. Focusing on the market demand, many leading manufactures are providing a range of sensors, robots and other heavy machinery to deliver the sensed data. This article is a compendium of knowledge that can help the researchers and agriculture engineers implementing the IoT-based technologies to achieve the desired smart agriculture.

\section{Application Domains of IoT in Agriculture}

IOT is a progressive innovation that speaks to what's to come for figuring and correspondence. It alludes to a system of question and self-designing remote system. The reemerging of worldwide subsidence has brought on swells over both the created and creating economies. Farming segment will have a great deal more effective to guarantee worldwide nourishment security. IOT applications include various zones including agriculture, human services, retail, transport, environment, production network administration, foundation observing and so on. Applications in agriculture incorporate soil and plant observing, green house environment checking and control framework observing of natural pecking order supply. The systems administration of things must be savvy and helpful to the end clients for acknowledgment and wide scale appropriation of IOT. The IOT is an overall system of inter-communicating gadgets. It incorporates unavoidable processing and encompassing insight.
IOT will associate the world's items in both a tangible and clever way through joining innovative improvements like sensors and remote sensor systems, installed frameworks and with nanotechnology. The accompanying advances straightforwardly add to improvement of IOT: Machine to machine interface, Protocols of electronic correspondence, Energy gathering advancements, sensors, actuators, GPS, Software. The accompanying advances may enhance the IOT: labeling/Geo-storing, Bio measurements, Machine vision, Robotics, telepresence, Adjustable Autonomy, life recorders, Personal secret elements, clean advancements. The available, moderate, intuitive group sourcing stage for reasonable agriculture would give a method for sharing data like devices, procedures, feasible farming techniques etc., It address nourishment security, water security, the arrangement must accommodates issues, smaller scale back administrations for ranchers should likewise give a unified store to an assortment of data for example, conventional reasonable cultivating procedures, edit ailment and so forth,. The elements of agriculture segment, for example, differing qualities, multifaceted nature patio worldly fluctuation in building up the correct sorts of items and gadgets. The size of homesteads shifts from little to expansive and thus the arrangements ought to be versatile. The IOT is an innovative upset that speaks to the fate of processing and correspondence furthermore, its improvement relies on upon advancement from remote sensors to nanotechnology.

By 2050, almost 10 billion is the projected world's population furthering agricultural demand as part of the economic growth. This raises innumerable questions like can we meet the required production increase with the scarce water and land resources in the face of drastic global climatic changes already plaguing the world? 
Technology is the enabler that will steer Indian farming towards an inclusive and sustainable farming to meet the agricultural requirement of the future. New technologies like Artificial Intelligence, Farm and Data Analytics, Aerial image-based analytics are being introduced by Agri-tech start-ups in India to make farming processes more efficient and lead to better decisions for improving yield and productivity.

\section{Smart farming technologies to the rescue}

The Indian agricultural landscape is witnessing an onslaught of new technologies like drones; farm based mobile applications, and hi-tech sensors that connect buyers and sellers with important farm-related information among others. According to a research, the Global Smart Farming market is set to grow at a compound annual growth rate of around $13 \%$.

Smart Farming IoT is the most visible farming technology that combines sensors and analytics to automate, monitor, or enhance and improve agricultural operations and processes. This is fueled by the Big Data phenomenon where IoT enabled sensors collect information on soil moisture, weather, fertilization cycles etc. and transmit that data over internet and cloud to a central hub for analysis. This enables farmers with real time access to information about their livestock, land, logistics and farm machinery.

Several Open source smart farming IoT platform offer solutions like Sensor-based field and resource mapping, Remote equipment monitoring, Predictive analytics for crops and livestock, Remote crop monitoring, Livestock tracking and Geofencing, Climate monitoring and forecasting among others. By tying together different sensors, connected devices, and farming facilities, Smart farming technologies allow better and practical decision making to predetermine the optimal usage of water and other agricultural inputs including seeds, fertilizers, etc.

\section{Securing the future}

While Smart technologies will continue to influence Indian farming, the looming concern is the vulnerability to cyber threats from hostile attackers. Securing the platform with embedded firewall when upgrading or replacing older legacy systems, stringent risk analyses to understand where vulnerabilities may be and how best to address them and applying analytics to derive definitive insights will play a major role. The exponential amount of data that these smart farming applications reveal and benefit the farmers is unbelievable and it's estimated that this will be roughly one million data points generated per day from an average smart farm. This will, no doubt, lead to further innovations in agricultural technology.

The primary focus of each IoT agricultural application concerning their domains (monitoring, controlling, and tracking) The main classification of these applications are Irrigation Monitoring and Controlling (16\%), Precision Farming (16\%), Soil Monitoring (13\%), Temperature Monitoring (12\%), Humidity Monitoring (11\%), Animal Monitoring and Tracking (11\%), Water Monitoring and Controlling (7\%), Disease Monitoring (5\%), Air Monitoring (5\%), and Fertilization Monitoring (4\%), as shown in Figure 2a. Farooq et al., (2020) reported that IoT agricultural applications monitor, control, and track the different precision farming, greenhouse, and animal-related parameters. Sensors/devices produce valuable data by sensing and monitoring multiple field variables through WSN. The data generated through sensing and monitoring devices are transferred through the communication 
protocols on other platforms for a user or farmer view (Figure 2b). Yoon et al., (2018) also found that by using IoT, farmers can manage soil condition more effectively and at less expense by monitoring them from any location focused on environmental temperature (24.87\%), humidity (19.79\%) and soil moisture $(15.73 \%)$ as environmental measurements.

Li et al., (2010) revealed that the sensors are used to monitor and to measure different farm variables (example soil nutrients, weather data) and factors that affect production. The sensors can be classified into location sensors, optical sensors, mechanical sensors, electrochemical sensors, and airflow sensors (Figure 3a). These sensors are used to gather information, such as air temperature, soil temperature at various depths, rainfall, leaf wetness, chlorophyll, wind speed, dew point temperature, wind direction, relative humidity, solar radiation, and atmospheric pressure. There are key characteristics of IoT device that makes them suitable for agriculture purposes. They are: 1) power efficiency; 2) memory; 3) computational efficiency; 4) portability; 5) durability; 6) coverage; 7) reliability; and 8) cost.

Athani and Tejeshwar (2017) observed that in a developing country such as India, IoT interventions and applications are mostly confined to sectors other than agriculture (Figure 3b). These climate changes directly affect every factor associated with farming. Quick solutions are needed for handling this issue. IoT uses multiple sensors that are embedded in the fields, which collect realtime information regarding soil moisture weather information, temperature, dampness, precipitation, soil composition, soil temperature, leaf wetness, air quality, predicting pests, crops, water level, etc. Such analytical statistical data provides helpful information to the cultivator in a smarter way that helps to get the decision very precisely (Siddagangaiah, 2016).

IoT control systems use a bi-directional information channel, unlike monitoring system, where the user has unidirectional information channel for data transmission over WSAN (Wireless Sensor and Actuator Network) for controlling a group of actuator devices to change the state of the process, which was being controlled by the IoT system. A new communication method was added, and instructions could be sent back to the device deployed in the agriculture field. This system helps the farmer by reducing water consumption and by providing the facilities for optimum usage of pesticides and fertilizers. Overall, solutions with control systems could save money to the farmers by providing mechanisms based on data sensors for the consumption of water, fertilizers, pesticides, and electricity.

Venkatesan et al., (2018) revealed that IoT based intelligent devices, such as wireless sensors, robots and drones are allowing the growers to slash pesticide uses significantly by precisely spotting crop enemies. Compared to traditional calendar or prescription based pest control procedures, modern IoT-based pest management provides real-time monitoring, modeling, disease forecasting, hence proving more effective. Generally, the reliability of crop disease monitoring and pest management depends on three aspects: sensing, evaluating, and treatment. The advanced disease and pest recognition approaches are based on image processing in which raw images are acquired throughout the crop area using field sensors, UAVs, or remote sensing satellites. Usually, remote sensing imagery covers large areas and, hence, offers higher efficiency with lower cost. On the other hand, field sensors are capable to support more functions in collecting data, like environment sampling, 
plant health, and pest situations, in every corner throughout the crop cycle. For example, IoT-based automated traps can capture, count, and even characterize insect types, further uploading data to the Cloud for detailed analysis, which is not possible through remote sensing.

Sensors are exceptionally valuable as far as precision agriculture is concerned. Unpredictable or inadequate precipitation can be an impediment causing low yields and even crop failure. In addition, the aggregate sum of water can't be surveyed during the developing phases of the plant's growth (Akhil et al., 2018). From this paper the origins and need for Precision Agriculture was discovered and how it in its rudimentary form was implemented on large scale settings along with the feasibility of adapting these origin settings in developing nations in small farm settings. (Babu, (2013) revealed through this study it was understood how Precision Agriculture can possibly be implemented to maximize production efficiency and agricultural uniformity, further better the crop quality. A proposed architecture using IoT principles designed for precision agriculture applications is also critiqued. This architecture collects the required information and relays it to a cloud-based back-end where it is further processed and required analysis is done (Khattab et al., 2016).

Parameters through which analysis is done are Moisture in the soil, Temperature and Humidity around the crop/plant and the intensity of the light. Based on the readings sensed, suitable analysis is done. Adding on to this, the possibility of using sensor nodes to send such measurements to the cloud is also assessed by the creation of an Android application as an effective output viewer. Dholu and Ghodinde, (2018) reported through this paper an approach is observed which features a defined soil: crop database, readymade crop calendars and real-time values gathered through sensors. Baskar and Gnansekaran, (2017) have proposed a low rate DDoS attack detection algorithm which combines four different models. Each model works based on the traces of previous access. This needs huge amount of data to be transferred between the controlling devices to the source which manipulate the data to identify the low rate attack.

\section{Driverless machines}

Machine automation is not a new concept, as agriculturalists consistently have found ways to automate their equipment through IoT powered driverless machines bring automation to the next level. First, there is a slice in the costs required to pay laborers to man farm machines like tractors, seed drills, cultivators, and tillers, though the benefits of driverless machines do not stop with labour reductions. Driverless machines become far more compact and lightweight when AC units, seating, and the entire cab sections are removed. Less power is required to run the smaller machines.

Many farming equipment pieces started as compact devices that one person could quickly handle in their inception. To cut back on labour costs and time, these machines were engineered to become bigger to execute several iterations of a repetitive task in one fell swoop, like a tractor that can till five rows at once. In cases such as this, however, failure in one large machine results in significant downtime. Returning to larger quantities of smaller, unmanned units addresses both concerns by providing the positive impact of minimizing laborers and reducing the massive loss of production time due to outages in larger machines. Furthermore, machines, like seeding units, are superior when smaller less weight means fewer soil compaction issues that cause yield reductions. 
Live technology use-cases in agriculture from across the world

For agriculture to become profitable, farmers need to improve their existing practices and adopt technology for sustainable water management, food production and environmental monitoring. Ranch Systems has designed weather stations and several other IoT agricultural products, including wireless network-connected soil probes. By continuously receiving updates regarding soil conditions, farmers can keep a close eye on water usage with these probes and conserve nutrient-rich soil by irrigating according to definitive soil condition readings. Such precise maintenance can reduce plant stress and increase root systems' growth by keeping moisture levels consistent. Similar environmental equipment can monitor local disease and pest threats to curb any excessive use of pesticides.

Tractors form an integral part of farm mechanization and have a crucial role to play in increasing agricultural productivity. In India, less than 30 percent of farmers use the necessary equipment that facilitates productive and profitable work. Farmers can barely afford high-cap equipment and often take loans to buy them. This often adds onto the financial burden in a bad crop yield season. Also, small farmers often lack knowledge about modern farming practices or struggle to finance farm operations. Hello Tractor brought the concept of 'Uberisation of Tractor's to life! Hello Tractor has deployed the Aeris Mobility Platform for tractor tracking, utilization time and simplified billing, based on time in the field and area covered, enabling them to adopt the pay-asyou-use model for small holding farmers to use tractors with innovative commercial models. Hello Tractor's innovative use of IoT simplifies complex data to ensure transparency, profitability, and accountability across the ecosystem of farmers, tractor owners, tractor dealers, original equipment manufacturers, banks, and governments. The Tractor Owner App includes tools such as, service request management, tractor and fleet management, operator performance, and activity tracking. Using the technology to their advantage, the farmers can plant 40 times faster at one-third the cost. The digital IoT platform is making it easy and profitable for tractor owners to monetize their machines as business assets whilst improving the livelihood of rural farmers.

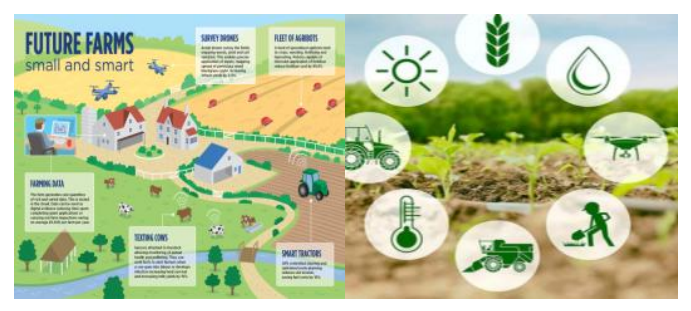

\section{Environment and micro-climate tracking}

The agriculture industry and automation suppliers are exploring now opportunities for using IoT and digital solutions for improving yields, profitability, and farming practices. From having sensors in farm and farm equipment, providing real-time data availability and alarms, to advanced analytics for taking corrective and preventive actions, IoT based smart farming will make it streamlined and more predictable. Recognizing the unique needs of the agriculture sector, companies have developed software platforms and apps for yield management, resource management, livestock management, and crop monitoring; including addressing issues that impact crop quality, productivity, and most importantly the cost. IoT is transforming traditional semiautomated weather stations into wireless units that give core climate framework information and give exact micro-climate data. These weather monitoring units' alert farmers through an application on their phone or data 
center when acute risks, such as damaging frosts and heat waves, arise in areas local to their farms.

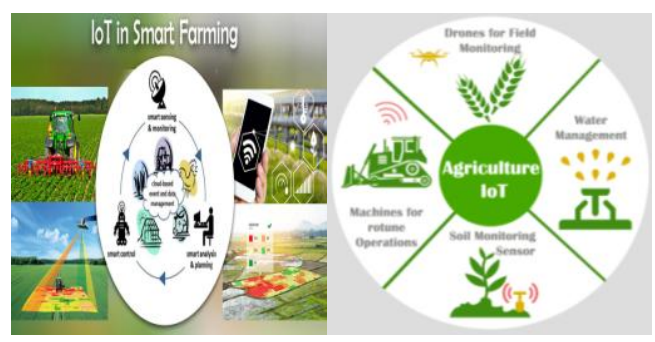

\section{Smart farming for tackling production costs and operational challenges}

The agriculture industry and automation suppliers are exploring now opportunities for using IoT and digital solutions for improving yields, profitability, and farming practices. From having sensors in farm and farm equipment, providing real-time data availability and alarms, to advanced analytics for taking corrective and preventive actions, IoT based smart farming will make it streamlined and more predictable. Recognizing the unique needs of the agriculture sector, companies have developed software platforms and apps for yield management, resource management, livestock management, and crop monitoring; including addressing issues that impact crop quality, productivity, and most importantly the cost.
Crop forecasting is an art to predict the yield and production (tons/ha) before the harvest takes place. This forecasting helps the farmer for near-future planning and decision making. Furthermore, analyzing the yield quality and its maturity is another critical factor which enables the determination of the right time for harvesting. This monitoring covers various development stages and uses fruit conditions like its color, size, etc., for this purpose. Predicting the right harvesting time not only helps to maximize the crop quality and production but also provides an opportunity to adjust the management strategy. Although, harvesting is the last stage of this process, proper scheduling can make a clear difference. To obtain the real benefits from crops, farmers need to know when these crops are actually ready to harvest. Figure 4a represents a snapshot of a farm area network (FAN) that can portrait the whole farm to the farmer in real time. Figure $4 \mathrm{~b}$ presents a snapshot of major challenges that future agriculture expected to face in 2050. This diagram, basically presents three major issues: how to feed around 10 billion people; without using more land and; by reducing the emission of greenhouse gasses by more than $60 \%$. However, when we look closely then these three challenges lead to many new, including smaller rural labor, continuously shrinking arable land, water scarcity, harsh weather conditions, and many more.

Fig.1a Key Drivers of Technology in Agriculture Industry

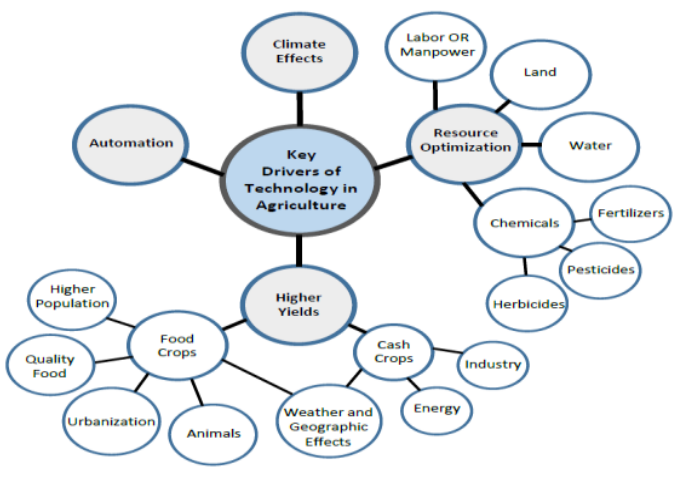


Fig.1b Major Hurdle's in technology implementation for smart agriculture

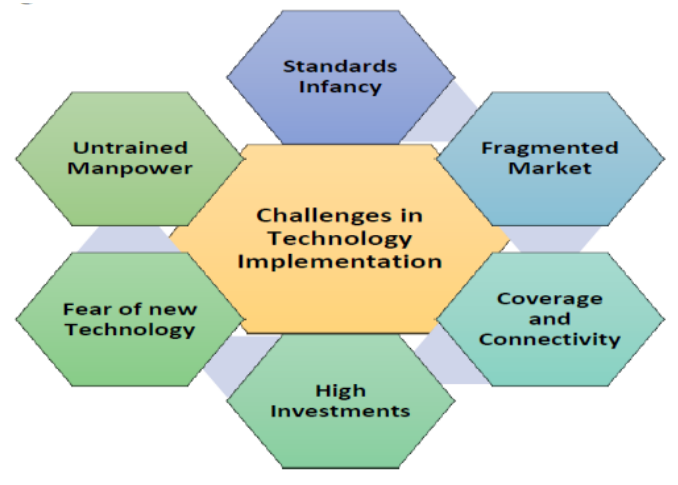

Fig.2a IoT agriculture applications

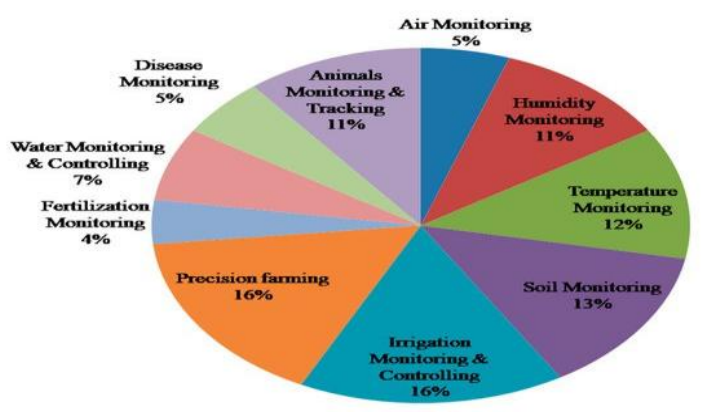

Fig.2b IoT agricultural hierarchy

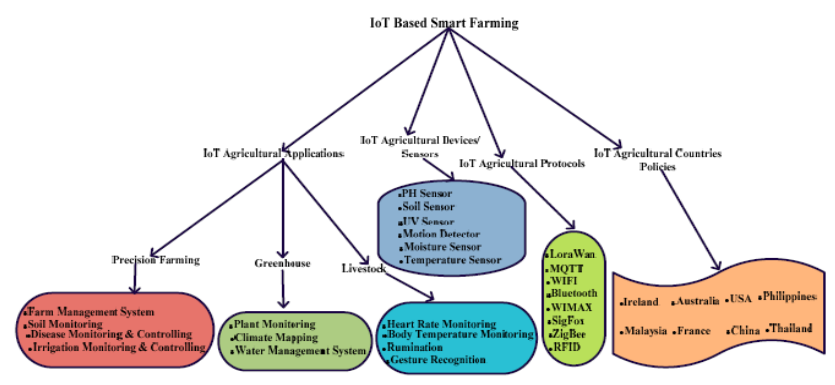

Fig.3a Illustration of IoT ecosystem for agriculture

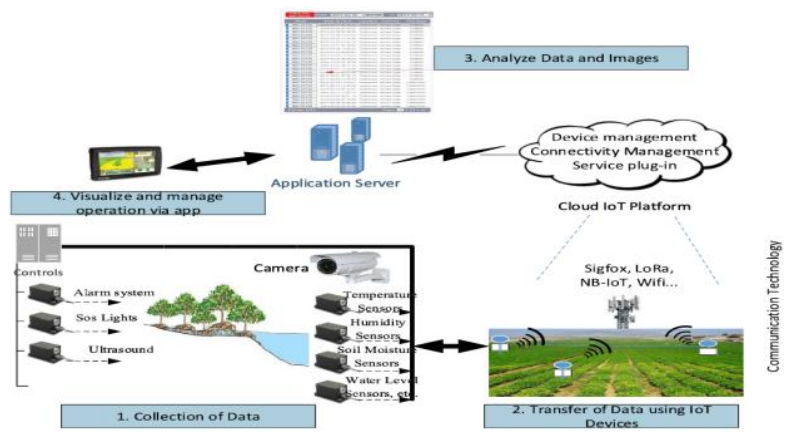


Fig.3b Hierarchical structure of usage of IoT in Agriculture

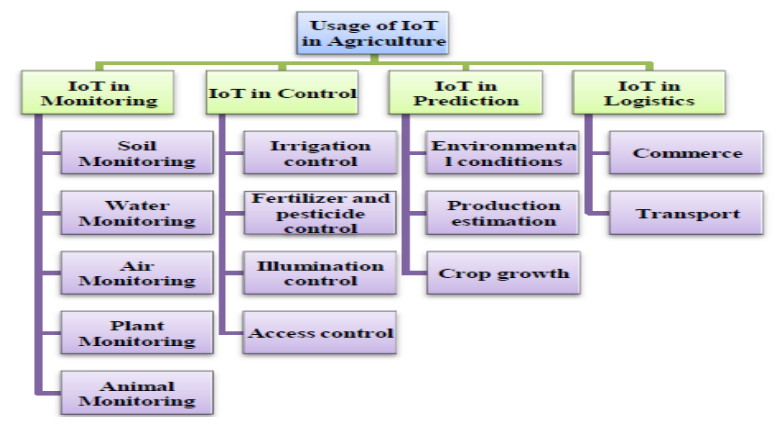

Fig.4a An IoT based Farm Area Network (FAN)

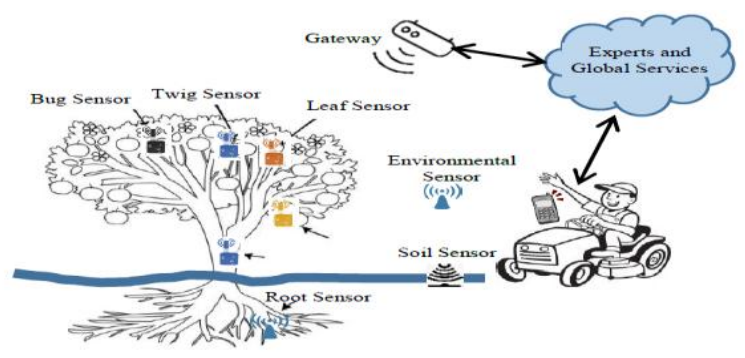

Fig.4b Major challenges for sustainable future agriculture
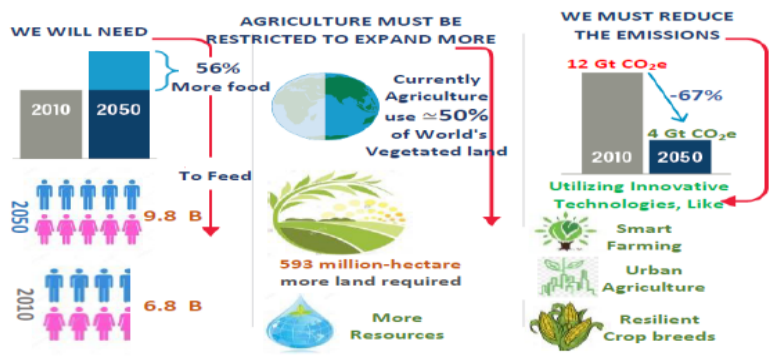

As the world moves toward urbanization, the rural populations are not only shrinking but are rapidly aging; hence, fewer and younger growers need to step up to take the responsibility. Such population imbalance and generation shift can create serious implications, not only for the remaining workforce but also for production patterns and land tenure. Furthermore, on one side, arable land is shrinking while, among the remaining regions, many are only suitable for specific crops due to certain geographic and environmental limitations. Moreover, harsh climate changes are starting to affect almost every aspect of crop production. These changes are expected to enhance the intensity of many of the existing long-term environmental issues, like droughts, floods, groundwater depletion, soil degradation, etc. Considering this scenario, future agriculture is expected to evolve as a high-tech industry where interconnected systems will enjoy the luxury of artificial intelligence and Big Data facilities. The resultant systems will converge into a single unit where farm machinery and management, starting from seeding to production forecasting, are combined. By involving the advanced technologies like 
agricultural robots, Big Data, and cloudcomputing artificial intelligence, agriculture can create a new era of super fusion. Following are some of the key technologies and methods that need to apply; focusing to achieve sustainable future agriculture.

In conclusions the agriculture technologies have changed and continuously cooperating to change almost all the domains of farming from sowing to harvesting. These technologies are continued to evolve and invent new innovations that act as catalyst to ameliorate farmers' life by increasing incoming and providing the access to research stations and agro-scientists. The interventions of IoT is not only changing the way agriculture has been thriving to survive but also innovate novice ideas by spreading awareness about the pragmatic application of using technology on ground level. The use of technology can make farmers feel more empowered and enable them to adopt required measures in needful time. It has potential capabilities to transform agriculture into a better prospect to get aware of climatic change and appropriate use of limited natural resources in agricultural land. There is a lot of innovation in the Internet of Things, have the potential to make a huge impact on the farm.

With continuous improvement in technology, IoT will bring revolution in the agriculture field. Growing number of smart IoT devices are helping farmers in collecting meaningful data. Farmers should understand the power and potential of IoT for agriculture. As the population is increasing rapidly, farmers can successfully meet the demands. While Smart technologies will continue to influence Indian farming, the looming concern is the vulnerability to cyber threats from hostile attackers. Securing the platform with embedded firewall when upgrading or replacing older legacy systems, stringent risk analyses to understand where vulnerabilities may be and how best to address them and applying analytics to derive definitive insights will play a major role. The exponential amount of data that these smart farming applications reveal and benefit the farmers is unbelievable and it's estimated that this will be roughly one million data points generated per day from an average smart farm. This will, no doubt, lead to further innovations in agricultural technology. On the other hand, (IoT) is transforming the agriculture industry so that farmers can master the enormous challenges. As the industry still to overcome growing water scarcity, limited land supply, the difficulty of managing costs and meet the growing demand for world consumers, which is expected to grow by 70 percent by 2050 . Moreover, using IoT still open the doors for agriculture industry and farmers through improve the quality, quantity, sustainability and cost effectiveness of agricultural production by implementing them into reality as it's the only promising in $21^{\text {st }}$ century.

\section{References}

Akhil, R., Gokul, M. S., Menon, S., and Nair, L.S. 2018. Automated Soil Nutrient Monitoring for Improved Agriculture. International Conference on Communication and Signal Processing (ICCSP), IEEE, Chennai, India, p.06880692 (2018)

Athani, S. and Tejeshwar, C. H. 2017. Soil moisture monitoring using IoT enabled arduino sensors with neural networks for improving soil management for farmers and predicts seasonal rainfall for planning future harvest in North Karnataka - India. ISMAC, IEEE. 43-48.

Babu, S. 2013. A software model for precision agriculture for small and marginal farmers. Global Humanitarian Technology Conference: South Asia Satellite (GHTC-SAS), DOI: 10.1109/GHTC-SAS.2013.6629944

Baskar, M., and Gnansekaran, T. 2017. 
Developing Efficient Intrusion Tracking System using Region Based Traffic Impact Measure towards the Denial of Service Attack Mitigation. Journal of Computational and Theoretical Nanoscience, 14(7):3576-3582.

Dholu, M., and K. A. Ghodinde, K.A. 2018. Internet of Things (IoT) for Precision Agriculture Application. . In Proceedings of the $20182^{\text {nd }}$ International Conference on Trends in Electronics and Informatics (ICOEI), Tirunelveli, India, 11-12 May 2018; pp. 339-342

Khattab, A., Abdelgawad, A., and Yelmarthi, K. 2016. Design and implementation of a cloud-based IoT scheme for precision agriculture. $28^{\text {th }}$ International Conference on Microelectronics (ICM) DOI: 10.1109/ICM.2016.7847850

Li, S., Simonian, A., and B. A. Chin, B.A. 2010. Sensors for agriculture and the food industry. Electrochem. Soc. Interface, 19 (4):41-46.

Elijah, O., Rahman, T. A., Orikumhi, I., Leow, C.Y., and Hindia, M.N. 2018. An Overview of Internet of Things (IoT) and Data Analytics in Agriculture: Benefits and Challenges, in IEEE Internet of Things Journal, 5 (5):3758-3773.

FAO 2013. Climate-Smart Agriculture Sourcebook. Source-book on Climate-Smart Agriculture, Forestry and Fisheries.

Farooq, M. U., and Waseem, M. 2015. A Review on Internet of Things (IoT). Int J Computer Applications (0975 8887), 113(1): 1-7.

Farooq, M.S., Riaz, S., Abid, A., Wmer, T., and Zikria, Y. B. 2020. Role of IoT Technology in Agriculture: A Systematic Literature Review. Electronics 9: 319; doi:10.3390/electronics9020319

Hi, X., An, X., Zhao, Q., Liu, H., Xia, L., Sun, X., and Guo, Y. 2019. State-of-the-Art Internet of Things in Protected Agriculture. Sensors, 19: 1833.

Li, S. Simonian, A., and Chin, B.A. 2010. Sensors for agriculture and the food industry, Electrochem. Soc. Interface, vol. 19(4): 41-46.

Navulur, S., Sastry, A.S.C.S., Giri Prasad, M.N. 2017. Agricultural Management through Wireless Sensors and Internet of Things. International Journal of Electrical and Computer Engineering (IJECE) 7(6):3492-3499.

Siddagangaiah, S. 2016. A Novel Approach to IoT Based Plant Health Monitoring System. Int Res J Engg Tech. (IRJET), 3(11): 880-886.

Venkatesan, R., Kathrine, G., Jaspher W., and Ramalakshmi， K. 2018. Internet of Things Based Pest Management Using Natural Pesticides for Small Scale Organic Gardens. Journal of Computational and Theoretical Nanoscience, 15: 9-10.

World agriculture: towards $2015 / 2030$ by FAO, 2019 Available at www.fao.org/3/ay4252e.pdf

Yoon, C., Huh, M., Kang, S., Park, J., and C. Lee, C. 2018. Implement smart farm with IoT technology in $20^{\text {th }}$ Int Conf on Advanced Communication Technology (ICACT).

Zhang, L., Dabipi, I. K. and Brown, W. L. 2018. "Internet of Things Applications for Agriculture". In, Internet of Things A to Z: Technologies and Applications, Q. Hassan (Ed.)

\section{How to cite this article:}

Pradeep Kumar Singh, R. K. Naresh, Akash Kumar, Lalit Kumar, M. Sharath Chandra, Shivangi and Prasant Ahlawat. 2021. Role of IoT Technology in Agriculture for Reshaping the Future of Farming in India: A Review. Int.J.Curr.Microbiol.App.Sci. 10(02): 439-451. doi: https://doi.org/10.20546/ijcmas.2021.1002.052 